\title{
Dietary fatty acids and insulin secretion
}

\author{
G. Mingrone
}

Department of Internal Medicine, Catholic University, School of Medicine, Rome, Italy

Abstract

It is well known that free fatty acids (FFAs) play a central role in insulin resistance. However, increasing evidence suggests that they are also implicated in the control of pancreatic insulin secretion. Simultaneous exposure of pancreatic $\beta$-cells to high levels of glucose and to saturated FFAs results in a substantial increase in insulin release, whereas chronic exposure may lead to a desensitization and suppression of secretion. A source of fatty acid, either exogenous or endogenous, is necessary to support normal insulin secretion. A rapid increase in fatty acids potentiates glucose-stimulated secretion by increasing the concentration of fatty acyl-coenzyme A or complex lipids, which act indirectly by modulating key enzymes, such as protein kinase C, or directly by modulating the exocytotic machinery. Mathematical models including FFAs in controlling insulin secretion are devised. Finally, insulin secretion in a human model of very low-fat diet, the malabsorptive bariatric surgery for morbid obesity, is described.

Keywords: fatty acids; insulin secretion; mathematical models; bariatric surgery

Abbreviations: ACC: acetyl-coenzyme A carboxylase; ATP: adenosine triphosphate; BPD: biliopancreatic diversion; CoA: coenzyme A; FAS: fatty acid synthase; FFA: free fatty acid; GIP: glucose-dependent insulinotropic peptide; GLP: glucagon-like peptide; GSIS: glucose-stimulated insulin secretion; IVGTT: intravenous glucose tolerance test; MUFA: monounsaturated fatty acid; SFA: saturated fatty acid; ZDF rat: Zucker diabetic fatty (falfa) rat.

\section{Introduction}

A lthough there is a large body of literature showing that free fatty acids (FFAs) play a pivotal role in the cellular mechanisms involved in insulin resistance (1-4), relatively few reports deal with the role of FFAs in the insulin secretion process.

In 1969, Crespin et al. (5) reported that a rapid onset of a two- to 12-fold increase in plasma insulin was observed in conscious dogs with acutely rising FFA concentration during infusion of sodium oleate into the circulation. The magnitude of the insulin response correlated with the mean FFA level during infusion. This observation remained isolated for about a decade.

In 1979 Campillo et al. (6) showed that in the isolated perfused pancreas of rat, oleic and octanoic acids potentiated glucose-induced insulin release without modification of the pattern of secretion. Thereafter, from time to time, isolated studies showed the effect of FFAs in increasing insulin secretion. Vara and Tamarit-Rodriguez (7) found that palmitate increased the insulin response of fed islets to glucose in a dose-related manner. In 1990 Sako and Grill (8) observed that in experimental animals hyperlipidaemia was associated with shortterm stimulation, but long-term inhibition, of glucose-induced insulin secretion. Wolf et al. (9) described that glucose-induced phospholipid hydrolysis and free arachidonate accumulation in pancreatic islets may play a role in the signalling process leading to insulin secretion.

The role of lipotoxicity (10) in the derangement of the insulin secretory capacity of $\beta$-cells is evident in obese Zucker diabetic fatty (ZDF falfa) male rats, which have a leptin receptor mutation and consequent hyperleptinaemia. In these animals, a model of type 2 diabetes mellitus, the inability of leptin to suppress insulin secretion results in chronic hyperinsulinaemia and increases the de novo lipogenesis in pancreatic islets $(11,12)$. Enhanced activity of fatty acid synthase (FAS), a key insulin-sensitive enzyme in lipogenesis, and overaccumulation of fat in pancreatic islets of obese ZDF rats, induce $\beta$-cell failure, resulting in frank diabetes (13).

The progression from insulin hypersecretion associated with insulin resistance to insulin secretion failure in male ZDF rats is a function of lipid accumulation in pancreatic $\beta$-cells. These rats develop progressive insulin resistance and glucose 
intolerance between 3 and 8 weeks of age and become overtly diabetic between 8 and 10 weeks; the development of diabetes is associated with a 10 50-fold increase in islet triglyceride content (14).

It has been shown that exogenous saturated long-chain fatty acids markedly potentiate glucoseinduced insulin release and elevate long-chain acylcoenzyme A ( $\mathrm{CoA})$ esters in the clonal $\beta$-cell line (15). The secretory action depended on the fatty acid chain length, occurred in the range 3-20 $\mu \mathrm{M}$ free palmitate concentration, and was reversible and inhibitable by the neuromodulator somatostatin.

When the elevated level of circulating FFAs in $18-24 \mathrm{~h}$ fasted rats was acutely lowered by infusion of the antilipolytic agent nicotinic acid, subsequent glucose-stimulated insulin secretion was completely ablated, but became supranormal when FFA concentration was maintained at high levels by coinfusion of a lipid emulsion plus heparin $(16,17)$. Qualitatively similar results have also been obtained in humans $(17,18)$. The axiom that glucose was the only secretagogue stimulus for pancreatic insulin secretion was, therefore, definitely refuted.

\section{Insulin secretion models}

When glucose concentration increases, insulin secretion is progressively stimulated. This dose-response relationship is depicted in Fig. 1. If the glucose concentration is briskly increased and maintained at a suprabasal level, insulin secretion shows an initial burst (first phase insulin secretion) followed by a gradually increasing secretion that approaches a nearly constant level after about $60 \mathrm{~min}$ (second phase insulin secretion). Prolonged exposure to hyperglycaemia determines a global increase in the insulin response, denoted as potentiation.

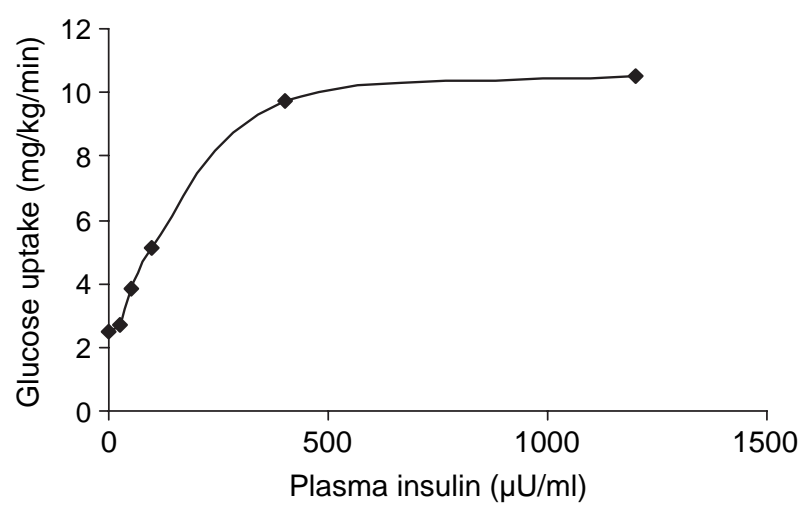

Fig. 1. Dose-response curve relating glucose uptake to insulin levels in normal subjects in conditions of euglycaemia.
The $\beta$-cell response to an oral glucose challenge, such as after an oral glucose tolerance test, is much higher than that observed during an intravenous glucose infusion at matched glucose levels, as a consequence of the intestinal incretin secretion, mainly represented by glucose-dependent insulinotropic peptide (GIP) and glucagon-like peptide-1 (GLP-1).

In insulin resistance states, $\beta$-cell function is increased to overcome the impaired insulin action at the level of peripheral tissues, such as skeletal muscle, and at the level of the liver, by increasing the glucose output.

The methods most often used for assessing insulin secretion include the intravenous glucose tolerance test (IVGTT) and the hyperglycaemic clamp, which is also the reference test for first phase insulin secretion. The arginine test is based on the observation that the intravenous injection of arginine produces a large burst in insulin secretion which is also dependent on the current glucose levels. In comparison with the IVGTT, the arginine test releases a larger pool of insulin granules. The physiological significance of this pool is unknown. The response to arginine is also present in diabetic subjects in whom the first phase after the IVGTT is lacking.

$\beta$-Cell insulin secretion is generally computed using the C-peptide deconvolution method (1921 ), which is based on a standardized model of C-peptide kinetics (22). In normal $\beta$-cells, the sensitivity-secretion relationship is expressed as a rectangular hyperbola (23). The product of insulin sensitivity and insulin secretory response equals a constant, named the "disposition index" (Fig. 2). Changes in insulin sensitivity are accompanied by compensatory modifications in $\beta$-cell sensitivity to glucose. Insulin resistance is accompanied by

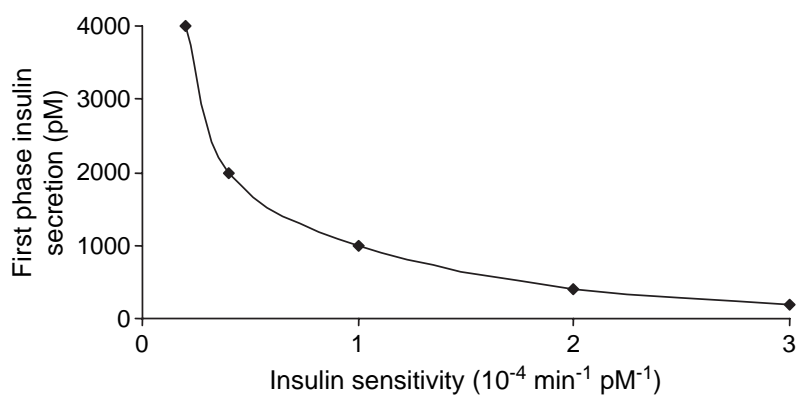

Fig. 2. Hyperbolic sensitivity-secretion curve. Note that when insulin sensitivity is reduced insulin secretion is increased as a result of an up-regulation of the $\beta$-cells' sensitivity to glucose. 
up-regulation of $\beta$-cell sensitivity, and thus hyperinsulinaemia, whereas higher insulin sensitivity is associated with a down-regulation of $\beta$-cell sensitivity.

\section{Mechanisms of stimulation of insulin secretion}

The role of fatty acids in controlling insulin secretion has been recently reviewed by Yaney and Corkey (24). These authors underline that a source of fatty acid, either exogenous or endogenous, is necessary to support normal insulin secretion. A rapid increase in fatty acid concentration potentiates glucose-stimulated secretion by increasing the concentration of fatty acyl-CoA or complex lipids that act indirectly by modulating key enzymes, such as protein kinase $\mathrm{C}$, or directly by modulating the exocytotic machinery. The hypothesis is that nutrients stimulate insulin secretion through the simultaneous activation of two pathways, one involving accelerated adenosine triphosphate (ATP) production and increased intracellular calcium cations, and the other depending on the generation and accumulation of excess citrate in the cytosol and on the increase in cytosolic malonyl-CoA, which in turn blocks long-chain acyl-CoA transport into mitochondria. Glucose-stimulated insulin secretion is associated with decreased FFA oxidation (24).

The signal transduction model in nutrient-induced insulin secretion postulates that increased glycolysis leads to accelerated ATP production and, consequently, to an increased ratio of ATP to adenosine diphosphate (ADP) (25). The increase in ATP in the $\beta$-cells closes the $\mathrm{K}_{\mathrm{ATP}}$ channel and determines the depolarization of the cell membrane, opening the voltage-dependent $\mathrm{Ca}^{2+}$ channels and raising the intracellular $\mathrm{Ca}^{2+}$. The rise in intracellular $\mathrm{Ca}^{2+}$ levels activates the kinase system, which controls insulin secretion, allowing the secretion granules of insulin to fuse with the cellular membrane, thus liberating insulin molecules. However, there is recent evidence that glucose-stimulated insulin secretion (GSIS) can also be independent of the $\mathrm{K}_{\text {ATP }}$ channel (26-28) and can be stimulated by other nutrients, such as FFAs. Further, the action of glucose in the absence of $\mathrm{Ca}^{2+}$ can be mimicked by FFAs (29).

According to the view that a dual signalling pathway is involved in the stimulation of insulin secretion by nutrients, a mathematical model in which insulin secretion rate is expressed as a function of both plasma glucose and FFA concen- trations has been proposed recently (30). Model parameters, obtained by fitting the individual experimental data of plasma C-peptide concentration, give an estimated insulin secretion rate comparable to that obtained by the deconvolution method. This inclusive model of nutrient-stimulated insulin secretion is the first attempt to represent in a simple way a complex molecular mechanism of regulation of insulin secretion in the $\beta$-cell, and explains, at least in part, the "potentiation factor" used in previous models (30) to account for control factors other than glucose.

\section{Dietary fatty acids and insulin secretion}

Dietary supplementation of n-3 fatty acids from marine oils in gold-thioglucose-injected CBA/T6 mice, an animal model of type 2 diabetes, led to an improvement in glycosylated haemoglobin associated with a higher plasma insulin concentration. This suggests that the metabolic effects of $n-3$ fatty acids were mediated by insulin hypersecretion, rather than by an enhancement of peripheral insulin sensitivity (31)

Monounsaturated fatty acids (MUFAs) exert a higher stimulatory effect on incretins than saturated fatty acids; however, this graded effect does not result in different insulin secretion. While a mixed meal constituting $80 \mathrm{~g}$ olive oil plus $50 \mathrm{~g}$ carbohydrates induced lower triacylglycerol and higher GLP-1 and GIP plasma concentrations than a mixed meal containing the same amount of butter, no differences in the concentrations of glucose, insulin and fatty acids were found (32).

In healthy volunteers, diets rich in saturated fatty acids (SFAs) or MUFAs exerted different effects on insulin sensitivity, with MUFAs improving and SFAs worsening insulin secretion, while $\beta$-cell function resulted unchanged (33).

The Finnish Diabetes Prevention Study showed that the incidence of type 2 diabetes mellitus was dramatically reduced by a 3 year intervention study, where the total fat intake was reduced to less than $30 \%$, with a content of SFAs lower than $10 \%$ (34). In contrast, in the Nurses' Health Study the total fat intake was not associated with the risk of diabetes mellitus after adjusting for other known risk factors. However, polyunsaturated fatty acid intake was related to a reduction in diabetes incidence, whereas trans fatty acids increased this risk (35). Finally, the 30 year dietary survey of Finnish, Italian and Dutch survivors of the Seven Countries Study showed that 
the incidence of diabetes was independent of dietary fat intake (36). Environmental and genetic factors, physical activity and other lifestyle-related factors should be taken in account to explain these apparently discordant results.

Increased levels of FFA may, through their effect on stimulating insulin secretion, have a protective event in reducing the development of diabetes in obese, insulin-resistant individuals. In obese people with normal pancreatic $\beta$-cells, FFAs are potent insulin secretagogues and can compensate for the insulin resistance that they produce. When chronically elevated plasma FFA levels were lowered in obese diabetic and non-diabetic subjects, insulin secretion rates decreased by $30-50 \%$ (37), indicating that the elevated plasma FFAs had supported 30$50 \%$ of basal insulin secretion. In contrast, in first degree relatives of patients with type 2 diabetes, FFAs are unable to compensate fully with adequately increased insulin secretion for the insulin resistance that they produce (38). This defect in FFA-stimulated insulin secretion can also be demonstrated in patients with impaired glucose tolerance (38) or with frank type 2 diabetes (38). These observations suggest that the obese individuals who develop type 2 diabetes may have a genetic predisposition to pancreatic $\beta$-cell failure.

\section{Malabsorptive bariatric surgery as a model of very-low fat diet}

Biliopancreatic diversion (BPD) is a bariatric surgical technique inducing massive lipid malabsorption and, therefore, it represents a fair model to evaluate how dietary lipid deprivation can affect glucose metabolism in humans. After BPD a large depletion of fats in the muscle cells was coupled with the normalization of insulin sensitivity (39). The insulin resistance reversion (40) probably occurred through a reduced tumour necrosis factor- $\alpha$ (41) and acetylcoenzyme A carboxylase (ACC) (42), and an increased GLUT4 mRNA expression (41). Pyruvate kinase gene expression was also reduced, resulting in a reduction in the inhibition of pyruvate dehydrogenase activity (43).

Modified BPD in two sisters, affected by familiar lipoprotein lipase deficiency, decreased serum triglycerides while improving insulin sensitivity and reversing type 2 diabetes (44). The complete reversion of type 2 diabetes after BPD is an early phenomenon appearing in the first few days after the operation (45).
Morbidly obese subjects with normal glucose tolerance, impaired glucose tolerance and type 2 diabetes show characteristically an increased fasting insulin secretion rate, while in type 2 diabetics $\beta$-cell glucose sensitivity is depressed with lower insulin output after a glucose load. Following BPD, fasting insulin secretion rate and total insulin output decreased, although a tendency towards an improvement in $\beta$-cell glucose sensitivity in impaired glucose tolerance and type 2 diabetes was observed (46). Furthermore, $\beta$-cell glucose sensitivity remained significantly impaired in type 2 diabetic subjects compared with lean controls. In conclusion, malabsorptive bariatric surgery was associated with a rapid improvement in $\beta$-cell glucose sensitivity and co-ordinated changes in insulin sensitivity and total insulin output, the latter decreasing as the former increased.

\section{References}

1. Colberg SR, Simoneau JA, Thaete FL, Kelley DE. Skeletal muscle utilization of free fatty acids in women with visceral obesity. J Clin Invest 1995; 95: 1846-53.

2. Kelley DE, Goodpaster B, Wing RR, Simoneau JA. Skeletal muscle fatty acid metabolism in association with insulin resistance, obesity, and weight loss. Am J Physiol 1999; 277: E1130-41.

3. Kelley DE, Kuller LH, McKolanis TM, Harper P, Mancino J, Kalhan S. Effects of moderate weight loss and orlistat on insulin resistance, regional adiposity, and fatty acids in type 2 diabetes. Diabetes Care 2004; 27: 33-40.

4. Bajaj M, Suraamornkul S, Romanelli A, Cline GW, Mandarino LJ, Shulman GI, et al. Effect of a sustained reduction in plasma free fatty acid concentration on intramuscular long-chain fatty acyl-CoAs and insulin action in type 2 diabetic patients. Diabetes 2005; 54: 3148-53.

5. Crespin SR, Greenough WB, Steinberg D. Stimulation of insulin secretion by infusion of free fatty acids. J Clin Invest 1969; 48: 1934-3.

6. Campillo JE, Valdivia MM, Rodriguez E, Osorio C. Effect of oleic and octanoic acids on glucose-induced insulin release in vitro. Diabete Metab 1979; 5: 183-7.

7. Vara E, Tamarit-Rodriguez J. Glucose stimulation of insulin secretion in islets of fed and starved rats and its dependence on lipid metabolism. Metabolism 1986; 35: 266-71.

8. Sako Y, Grill VE. A 48-hour lipid infusion in the rat time-dependently inhibits glucose-induced insulin secretion and $\mathrm{B}$ cell oxidation through a process likely coupled to fatty acid oxidation. Endocrinology 1990; 127: 1580-9.

9. Wolf BA, Pasquale SM, Turk J. Free fatty acid accumulation in secretagogue-stimulated pancreatic 
islets and effects of arachidonate on depolarizationinduced insulin secretion. Biochemistry 1991; 30: 63729.

10. Lee Y, Hirose H, Ohneda M, Johnson JH, McGarry JD, Unger RH. B-cell lipotoxicity in the pathogenesis of non-insulin-dependent diabetes mellitus of obese rats: impairment in adipocyte- $\beta$-cell relationships. Proc Natl Acad Sci USA 1994; 91: 10878-82.

11. Kieffer TJ, Heller RS, Leech CA, Holz GG, Habener JF. Leptin suppression of insulin secretion by the activation of ATP-sensitive $\mathrm{K}^{+}$channels in pancreatic $\beta$-cells. Diabetes 1997; 46: 1087-93.

12. Zhou Y-T, Shimabukuro M, Lee Y, Koyama K, Higa M, Ferguson T, et al. Enhanced de novo lipogenesis in the leptin-unresponsive pancreatic islets of prediabetic Zucker diabetic fatty rats: role in the pathogenesis of lipotoxic diabetes. Diabetes 1998; 47: 1904-8.

13. Shimabukuro M, Higa M, Zhou Y-T, Wang M-Y, Newgard CB, Unger RH. Lipoapoptosis in the $\beta$-cells of obese prediabetic $f a l f a$ rats: role of serine palmitoyltransferase overexpression. J Biol Chem 1998; 49: 32487-90.

14. Prentki M, Vischer S, Glennon MC, Regazzi R, Deeney JT, Corkey BE. Malonyl-CoA and long chain acyl-CoA esters as metabolic coupling factors in nutrient-induced insulin secretion. J Biol Chem 1992; 267: 5802-10.

15. Unger RH. Lipotoxicity in the pathogenesis of obesitydependent NIDDM. Genetic and clinical implications. Diabetes 1995; 44: 863-70.

16. Stein DT, Esser V, Stevenson B, Lane KE, Whiteside JH, Daniels MB, et al. Essentiality of circulating fatty acids for glucose-stimulated insulin secretion in the fasted rat. J Clin Invest 1996; 97: 2728-35.

17. Stein DT, Stevenson B, Chester MW, Basit M, Daniels $\mathrm{MB}$, Turley SD, et al. The insulinotropic potency of fatty acids is influenced profoundly by their chain length and degree of saturation. J Clin Invest 1997; 100: $398-$ 403.

18. Dobbins R, McGarry JD, Stein DT. Normal glucose stimulated insulin secretion is dependent on free fatty acids in the 24 - $^{\circ}$ to 48 -hour fasted human. Diabetes 1997; 46: $50-4$

19. Hovorka R, Jones RH. How to measure insulin secretion. Diabetes Metab Rev 1994; 10: 91-117.

20. Eaton RP, Allen RC, Schade DS, Erickson KM, Standefer J. Prehepatic insulin production in man: kinetic analysis using peripheral connecting peptide behavior. J Clin Endocrinol Metab 1980; 51: 520-8.

21. Polonsky KS, Rubenstein AH. Current approaches to measurement of insulin secretion. Diabetes Metab Rev 1986; 2: 315-29.

22. Van Cauter E, Mestrez F, Sturis J, Polonsky KS. Estimation of insulin secretion rates from C-peptide levels. Comparison of individual and standard kinetic parameters for C-peptide clearance. Diabetes 1992; 41: 368-77.

23. Bergman RN, Phillips LS, Cobelli C. Physiologic evaluation of factors controlling glucose tolerance in man: measurement of insulin sensitivity and B-cell glucose sensitivity from the response to intravenous glucose. J Clin Invest 1981; 68: 1456-67.

24. Yaney GC, Corkey BE. Fatty acid metabolism and insulin secretion in pancreatic beta cells. Diabetologia 2003; 46: 1297-312.

25. Prentki M, Tornheim K, Corkey BE. Signal transduction mechanisms in nutrient-induced insulin secretion. Diabetologia 1997; 40: S32-41.

26. Aizawa T, Sato Y, Ishihara F, Taguchi N, Komatsu M, Suzuki N, et al. ATP-sensitive $\mathrm{K}^{+}$channel-independent glucose action in rat pancreatic beta-cell. Am J Physiol 1994; 266: C622-7.

27. Gembal M, Detimary P, Gilon P, Gao ZY, Henquin JC. Mechanisms by which glucose can control insulin release independently from its action on adenosine triphosphate-sensitive $\mathrm{K}^{+}$channels in mouse B cells. J Clin Invest 1993; 91: 871-80.

28. Komatsu M, Schermerhorn T, Aizawa T, Sharp GW. Glucose stimulation of insulin release in the absence of extracellular $\mathrm{Ca}^{2+}$ and in the absence of any increase in intracellular $\mathrm{Ca}^{2+}$ in rat pancreatic islets. Proc Natl Acad Sci USA 1995; 92: 10728-32.

29. Komatsu M, Sharp GW. Palmitate and myristate selectively mimic the effect of glucose in augmenting insulin release in the absence of extracellular $\mathrm{Ca}^{2+}$. Diabetes 1998; 47: 352-7.

30. Mari A, Schmitz O, Gastaldelli A, Oestergaard T, Nyholm B, Ferrannini E. Meal and oral glucose tests for assessment of beta $\beta$-cell function: modelling analysis in normal subjects. Am J Physiol Endocrinol Metab 2002; 283: E1159-66.

31. Sullivan DR, Yue DK, Capogreco C, McLennan S, Nicks J, Cooney G, et al. The effects of dietary n-3 fatty acid in animal models of type 1 and type 2 diabetes. Diabetes Res Clin Pract 1990; 9: 225-30.

32. Thomsen C, Rasmussen O, Lousen T, Holst JJ, Fenselau $\mathrm{S}$, Schrezenmeir J, et al. Differential effects of saturated and monounsaturated fatty acids on postprandial lipemia and incretin responses in healthy subjects. Am J Clin Nutr 1999; 69: 1135-43.

33. Vessby B, Unsitupa M, Hermansen K, Riccardi G, Rivellese AA, Tapsell LC, et al. Substituting dietary saturated for monounsaturated fat impairs insulin sensitivity in healthy men and women: The KANWU Study. Diabetologia 2001; 44: 312-9.

34. Tuomilehto J, Lindstrom J, Eriksson JG, Valle TT, Hamalainen H, Ilanne-Parikka P, et al. Finnish Diabetes Prevention Study Group. Prevention of type 2 diabetes mellitus by changes in lifestyle among subjects with impaired glucose tolerance. N Engl J Med 2001; 344: 1343-50.

35. Schulze MB, Hoffmann K, Manson JE, Willett WC, Meigs JB, Weikert C, et al. Dietary pattern, inflammation, and incidence of type 2 diabetes in women. Am $\mathbf{J}$ Clin Nutr 2005; 82: 675-84.

36. Virtanen SM, Feskens EJ, Rasanen L, Fidanza F, Tuomilehto J, Giampaoli S, et al. Comparison of diets of diabetic and non-diabetic elderly men in Finland, The Netherlands and Italy. Eur J Clin Nutr 2000; 54: 181-6. 
37. Boden G. Free fatty acids - the link between obesity and insulin resistance. Endocr Pract 2001; 7: 44-51.

38. Perseghin G, Ghosh S, Gerow K, Shulman GI. Metabolic defects in lean nondiabetic offspring of NIDDM parents: a cross-sectional study. Diabetes 1997; 46: $1001-9$.

39. Greco AV, Mingrone G, Giancaterini A, Manco M, Morroni M, Cinti S, et al. Insulin resistance in morbid obesity: reversal with intramyocellular fat depletion. Diabetes 2002; 51: 144-51.

40. Mingrone G, DeGaetano A, Greco AV, Capristo E, Benedetti G, Castagneto M, et al. Reversibility of insulin resistance in obese diabetic patients: role of plasma lipids. Diabetologia 1997; 40: 599-605.

41. Mingrone G, Rosa G, Di Rocco P, Manco M, Capristo E, Castagneto $M$, et al. Skeletal muscle triglycerides lowering is associated with net improvement of insulin sensitivity, TNF-alpha reduction and GLUT4 expression enhancement. Int J Obes Relat Metab Disord 2002; 26: $1165-72$.

42. Mingrone G, Manco M, Granato L, Calvani M, Scarfone A, Mora EV, et al. Leptin pulsatility in formerly obese women. FASEB J 2005; 19: 1380-2.

43. Rosa G, Di Rocco P, Manco M, Greco AV, Castagneto M, Vidal H, et al. Reduced PDK4 expression associates with increased insulin sensitivity in postobese patients. Obes Res 2003; 11: 176-82.

44. Mingrone G, Henriksen FL, Greco AV, Krogh LN, Capristo E, Gastaldelli A, et al. Triglyceride-induced diabetes associated with familial lipoprotein lipase deficiency. Diabetes 1999; 48: 1258-63.

45. Guidone C, Manco M, Valera-Mora E, Iaconelli A, Gniuli D, Mari A, et al. Mechanisms of recovery from type 2 diabetes mellitus after malabsorptive bariatric surgery. Diabetes 2006; 55: 2025-31.

46. Mari A., Manco M, Guidone C, Nanni G., Castagneto $\mathrm{M}$, Mingrone $\mathrm{G}$, et al. Restoration of normal glucose tolerance in severely obese patients after bilio-pancreatic diversion: role of insulin sensitivity and beta cell function. Diabetologia 2006; 49: 2136-43.

Professor Geltrude Mingrone

Dipartimento di Medicina Interna

Catholic University

Largo A. Gemelli, 8

IT-00। 68 Rome

Italy

Tel: +3906 30154395.

Fax: + 39063054392

E-mail: gmingrone@rm.unicatt.it 